no changes of nomenclature. The placing of the family Phasmidae, a very isolated group, between the nearly related families Blattidae and Mantidae is the only point we would criticise in this connection, but the matter is of little consequence in a work of this character.

Of the 132 species of Dermaptera and Orthoptera recorded from New England no less than 28 species are introduced forms, among which are 5 species of earwigs, 14 of cockroaches, 3 mantids (none of which are established) and 6 saltatorial species.

The illustrations are well chosen and the three original coloured plates deserve special mention on account of the truthfulness of the figures in both form and colour.

Mr. Morse's book is a fine model for systematic workers to emulate and should rank as a classic in American entomology.

E. M. W.

\title{
ERRATA.
}

For Gunthrop read Gunthorp, p. 112, line 14.

For megachile read Megachile, p. 119, lines 5 and 18.

For argentate read argentata, p. 119, line 11.

For Tohitic read Tahiti, p. 119, line 16.

For Tahihan read Tahitan, p. 119, line 17.

For Trachea fanitima read finitima, p. 121, line 18.

For Mecistophalide read Mecistocephalide, p. 184, line 11.

For Urocerous read Urocerus, p. 216, line 13.

For flavcornis read favicornis, p. 216, line 6 from bottom.

\section{CHANGE OF ADDRESS.}

The Rev. Professor C. J. S. Bethune has left Guelph and is now residing at Toronto. His present address is as follows:

No. 16, Washington Ave., Toronto, Ont. 